\title{
Psychological and behavioural factors associated with sexual risk behaviour among Slovak students
}

\author{
Ondrej Kalina ${ }^{1}$, Andrea M Geckova ${ }^{1}$, Pavol Jarcuska ${ }^{2}$, Olga Orosova ${ }^{1}$, \\ Jitse P van Dijk ${ }^{1,3}$ and Sijmen A Reijneveld*3
}

\begin{abstract}
Address: ${ }^{1}$ Kosice Institute for Society and Health. Department of Educational Psychology and Health Psychology, Faculty of Arts, P.J. Safarik University, Moyzesova 50, Kosice, 04059, Slovakia, ${ }^{2}$ Department of Infectious Diseases, Faculty of Medicine, P.J. Safarik University, Tr. SNP 1 , Kosice, 04066, Slovakia and ${ }^{3}$ Department of Health Sciences, University Medical Center Groningen, University of Groningen, PO Box 30,001, 9700 RB Groningen, the Netherlands

Email: Ondrej Kalina - ondrej.kalina@upjs.sk; Andrea M Geckova - geckova@upjs.sk; Pavol Jarcuska - jarcuska@upjs.sk; Olga Orosova - olga.orosova@upjs.sk; Jitse P van Dijk - j.p.van.dijk@med.umcg.nl; Sijmen A Reijneveld* - s.a.reijneveld@med.umcg.nl

* Corresponding author
\end{abstract}

Published: 13 January 2009

BMC Public Health 2009, 9:15 doi:10.1 I86/147I-2458-9-15
Received: 26 May 2008

Accepted: 13 january 2009

This article is available from: http://www.biomedcentral.com/I47/-2458/9//5

(c) 2009 Kalina et al; licensee BioMed Central Ltd.

This is an Open Access article distributed under the terms of the Creative Commons Attribution License (http://creativecommons.org/licenses/by/2.0), which permits unrestricted use, distribution, and reproduction in any medium, provided the original work is properly cited.

\begin{abstract}
Background: Knowledge about the prevalence of sexual risk behaviour (SRB) in adolescence is needed to prevent unwanted health consequences. Studies on SRB among adolescents in Central Europe are rare and mostly rely on a single indicator for SRB. This study aims to assess the association of behavioural and psychological factors with three types of SRB in adolescents in Central Europe.
\end{abstract}

Methods: We obtained data on behavioural factors (having been drunk during previous month, smoking during previous week, early sexual initiation), psychological factors (self-esteem, wellbeing, extroversion, neuroticism, religiousness), and SRB (intercourse under risky conditions, multiple sexual partners, and inconsistent condom use) in 832 Slovak university students (response 94.3\%).

Results: Among those with sexual experience (62\%), inconsistent condom use was the most prevalent risk behaviour ( $81 \%$ in females, $72 \%$ in males). With the exception of having been drunk in males, no factor was associated with inconsistent condom use. Regarding the other types of SRB, early sexual initiation was most strongly associated. In addition, other, mostly behavioural, factors were associated, in particular having been drunk.

Conclusion: Results suggest that behavioural factors are more closely related to SRB than psychological factors. Associations differ by type of SRB and gender but offer few clues to target risk groups for inconsistent condom use. Results show a high need for health-promotion programmes in early adolescence that target SRB in conjunction with other health risk behaviours such as alcohol abuse. 


\section{Background}

Studies on sexual behaviour from Central and Eastern Europe (CEE) are scarce. The lack of information on sexual behaviour is most salient regarding late adolescence and young adulthood, when young people start to live without direct parental supervision. The best recent information available is based on the Health Behaviour in School-aged Children (HBSC) studies 2001/2002 and 2005/2006 [1]. In both studies (Slovakia is not included in the first one) adolescents from Central and Eastern Europe reported that they were less experienced with sexual intercourse, used contraception pills or condoms during their most recent sexual intercourse to a lesser degree and initiated sexual intercourse later in life than their peers from most Western countries. However, patterns in the sexual behaviour of adolescents and young adults in Central and Eastern Europe seem to be changing. A decrease in the age at which they become sexually active is evident, particularly among females, leading to a narrowing of the gap between boys and girls regarding the time of sexual initiation.

In the context of sexually-transmitted infections (STI), many studies show the inconsistent use of prophylactic methods (e.g. condoms) to be the main risk factor [2-4]. However, early sexual intercourse, having multiple sexual partners and the association with substance use should also be considered as significant risk factors in this age group. Although each of these factors can be considered as an aspect of risk-taking, none by itself is valid as an operationalisation of risk behaviour $[5,6]$; yet all have become important topics in health promotion.

The association of sexual risk behaviour (SRB) with a number of other risk behaviours, including substance use, is evident. Use of marijuana, cocaine or other illicit drugs by adolescents has been shown to be associated with increased rates of sexual intercourse in general, having multiple sexual partners and lower rates of condom use, particularly for users of illicit stimulant drugs [7]. Bingedrinking teens are approximately three times less likely to use condoms, and recent marijuana users are almost two times less likely to use condoms [8]. The increasing prevalence of alcohol, drugs and tobacco use among Slovak adolescents as reported in the ESPAD (European School Survey Project on Alcohol and Other Drugs) reports of 1995, 1999, 2003, 2007, [9-12] and the lack of scientific studies in this field in CEE countries led us to explore the association among this behaviour and sexual risk behaviour.

Early sexual initiation is related to multiple aspects of SRB, including inconsistent condom use, early pregnancy and a greater number of sexual partners $[13,14]$. Moreover, it is also a predictor of future gynaecological problems. Girls who reported having sexual intercourse before age 16 had significantly more symptoms such as vaginal discharge and pruritus and signs such as abnormal discharge, erythema of the vaginal mucosa and lower genital tract infections than girls who first experienced sexual intercourse after age 19 [15]. It was found that $81 \%$ of sexually experienced youth aged 12-14 wished they had waited longer to have sex, compared with 55\% of sexually experienced 15 to 19-year-olds [16]. Because of this we expect higher levels of SRB among those who report early sexual initiation.

SRB and other health-endangering behaviours may be considered the result of a number of determinants, which range from causal factors very close to the behaviour like attitudes and perceived social norms $[17,18]$ to more distant causal factors like personality, $[14,19,20]$ or even socioeconomic position [21]. As such, they may have shared causes with problem behaviour, as suggested by Jessor $[17,18]$. Thus, we might expect, for example, a co-occurrence with other problem behaviours, $[7,22]$ or with psychological factors.

A study by Reitman [20] which explored the role of selfefficacy and self-esteem found that adolescents who believe they could take "effective precautionary action to avoid HIV" had fewer sexual partners and reported more condom use than peers who had lower self-efficacy scores [20]. Low self-esteem has also been associated with inconsistent use of contraceptives among adolescent girls [14]. Various indicators of psychosocial distress, which frequently occur along with low self-esteem, have been found to be associated with more frequent sexual activity [23-26]. Furthermore, several studies included religiousness among the factors associated with SRB, although the results from these studies are not consistent.

Summing up, the aim of our study was to explore the association of behavioural (drinking, smoking, early sexual intercourse) as well as psychological factors (self-esteem, psychological well-being, extroversion, neuroticism, religiousness) with three aspects of SRB: (1) sexual intercourse under risky conditions, (2) multiple sexual partners and (3) inconsistent condom use among late adolescents.

\section{Methods \\ Sample}

Data were collected in April and November 2004. The sample consisted of 882 first-year students at two universities located in Kosice (230,000 inhabitants) P.J. Safarik University (7,000 students) and the Technical University (12,000 students) who during a compulsory lecture completed a questionnaire concerning health behaviour under the guidance of field workers. Students were 
recruited from a list of randomly selected study groups provided by the faculties concerned and their participation was voluntary. All procedures concerning data collection were explained to respondents before data collection. The Ethics Committee of the Medical Faculty of the P.J. Safarik University approved this study. Of the 882 students included, 7 left the room before the beginning and 43 were excluded afterwards because they left major parts of the questionnaire incomplete (altogether 50). A total of 832 responded (94.3\%), 355 male and 477 female, aged 19-28 years with $90 \%$ of the students aged $19-23$ years (mean 20.5; SD 1.4). Out of these, $45.1 \%$ studied at the science faculty, $34.8 \%$ at the technical faculty and $20.1 \%$ at the medical faculty. More than half of the respondents had completed grammar school, and the majority of the students lived in student halls of residence or with their parents.

\section{Measures}

Regarding $S R B$, respondents were asked (1) if they had had sex (penetration of vagina by the penis) after a short relationship or under the influence of drugs or alcohol (yes/no to any of the three conditions); (2) how many sexual partners they had had in their life ( 3 and less/4 or more); (3) how often they used condoms (always/almost always, occasionally, never).

Behavioural factors concerned binge drinking, smoking and early experience of sexual intercourse. Respondents were asked (1) how many times they had been drunk during the previous month (never/1 or more); (2) how many cigarettes they had smoked during the previous week (none/one or more) and (3) at what age they had had sexual intercourse for the first time. Those who had been drunk at least once during last month, smoked at least one cigarette per week and had sex before the age of 16 were indicated as behaving riskily. Categorisations regarding number of sexual partners, drunkenness and smoking were similar to ones that have been used previously [15,27-32].

Regarding psychological factors, self-esteem was assessed using the Rosenberg self-esteem scale [33]. The scale consists of 10 items ( 5 positive and 5 negative). Each item has a four-point scale ranging from "strongly agree" to "strongly disagree". For each question, the respondents choose the statement that most closely applies to them. The sum score for self-esteem varies from 10 to 40 , a higher score indicating higher self-esteem. This variable was trichotomised into high (30 to 40), middle (20 to 29) and low (10 to 19$)$.

Psychological well-being was measured with the shortened 12-item version of the General Health Questionnaire (GHQ12) [34]. The separate items focus on various aspects of respondents' psychological dispositions, for example problems with sleep, strain, happiness or stress. The questions compare how the respondents' present state differs from their usual state. The GHQ12 was scored using a four-point Likert scale $(0,1,2,3)$ with sum scores ranging from $0-36$. A higher sum score means lower psychological well-being. The values were trichotomised into high (0 to 11 ), middle (12 to 23 ) and low (24 to 36 ) psychological well-being.

Extroversion and neuroticism were measured with an abbreviated form of the revised Eysenck Personal Questionnaire [35]. Extroversion was measured with a 6-item scale (yes/no) as was neuroticism. The sum score for extroversion/neuroticism varies from 6 to 12 , with a higher score indicating lower levels of extroversion/neuroticism. Both variables were categorized into three levels: high ( 6 to 7 ), middle ( 8 to 10 ) and low (11 to 12 ) extroversion/neuroticism.

One item of the Questionnaire for Instrumental and Terminal Values [36] was used to measure religiousness. Respondents were asked to evaluate how important salvation (feeling of redemption, eternal life) is for them (1extremely important, 2-strongly important, 3-important, 4-less important and 5-unimportant). A higher score for this value indicates lower religiousness in the respondent. This variable was categorized into two levels: high (extremely important and strongly important) and low (important, less important and unimportant).

\section{Statistical analyses}

We first examined the proportion of students that had had sexual intercourse. Next, for those who had had intercourse at least once $(n=455)$, we examined, using logistic regression, the association of each indicator of SRB with behavioural and psychological factors separately for males and females. We computed crude odds ratios for each type of SRB in relation to each factor. Subsequently, we determined the mutually adjusted associations of factors with SRB by forward selection procedures, starting with all factors that had a statistically significant crude odds ratio. We repeated these analyses with addition of age into the models, which yielded very similar results (not shown). All analyses were done with SPSS software, version 14.00 .

\section{Results}

Table 1 presents a descriptive view of the behavioural and psychological factors separately for males and females. Of the 832 respondents, 455 reported having had sexual intercourse. Out of these, $44 \%$ of males versus $33 \%$ of females said they had had sex under risky conditions; $27 \%$ of males versus $21 \%$ of females said they had had 4 or more sexual partners in their life; $72 \%$ of males versus 
Table I: Sexual risk behaviour and other risk behaviour $(n=832)$

\begin{tabular}{|c|c|c|c|c|}
\hline & \multicolumn{2}{|c|}{ Male $(n=184)$} & \multicolumn{2}{|c|}{ Female $(n=27 I)$} \\
\hline & Number & $\%$ & Number & $\%$ \\
\hline \multicolumn{5}{|c|}{ Sexual experience * } \\
\hline Yes & 184 & 61.3 & 271 & 63.3 \\
\hline \multicolumn{5}{|c|}{ Having sex before age of 16} \\
\hline Yes & 15 & 8.5 & 13 & 5.1 \\
\hline \multicolumn{5}{|c|}{ Having sex under risky conditions } \\
\hline Yes & 81 & 44.3 & 87 & 32.8 \\
\hline \multicolumn{5}{|c|}{ Multiple sexual partners } \\
\hline Yes & 45 & 26.5 & 54 & 21.4 \\
\hline \multicolumn{5}{|c|}{ Inconsistent condom use } \\
\hline Yes & $|3|$ & 72.4 & 209 & 80.7 \\
\hline \multicolumn{5}{|c|}{ Being drunk at least once during last month } \\
\hline Yes & 88 & 48.1 & 79 & 29.3 \\
\hline \multicolumn{5}{|c|}{ Smoking one cigarette at least once per week } \\
\hline Yes & 80 & 44.2 & 101 & 38.3 \\
\hline \multicolumn{5}{|l|}{ Self-esteem } \\
\hline High & 51 & 28.7 & 66 & 25.3 \\
\hline Middle & 100 & 56.2 & 134 & 51.3 \\
\hline Low & 27 & 15.2 & 61 & 23.4 \\
\hline \multicolumn{5}{|c|}{ Psychological well-being } \\
\hline High & 51 & 27.9 & 56 & 20.9 \\
\hline Middle & 102 & 55.7 & 132 & 49.3 \\
\hline Low & 30 & 16.4 & 80 & 29.9 \\
\hline \multicolumn{5}{|l|}{ Extroversion } \\
\hline Low & 21 & 11.9 & 36 & 14.1 \\
\hline Middle & 87 & 49.4 & 114 & 44.7 \\
\hline High & 68 & 38.6 & 105 & 41.2 \\
\hline \multicolumn{5}{|l|}{ Neuroticism } \\
\hline Low & 60 & 32.8 & 47 & 17.9 \\
\hline Middle & 90 & 49.2 & $|3|$ & 49.8 \\
\hline High & 33 & 18.0 & 85 & 32.3 \\
\hline \multicolumn{5}{|l|}{ Religiousness } \\
\hline Strongly important & 65 & 43.0 & 95 & 42.6 \\
\hline Unimportant & 86 & 57.0 & 128 & 57.4 \\
\hline
\end{tabular}

* from whole sample - male $(n=355)$, females $(n=477)$

$81 \%$ of females reported inconsistent condom use and $9 \%$ of males versus $5 \%$ of females had had sex before age 16.

Tables 2 and 3 present the results of the logistic regression models analysing the associations of each indicator of SRB with the behavioural and psychological factors separately for males and females. Statistically significant $(p<0.05)$ associations are summarized below.

\section{Sex under risky conditions}

Males and females who reported having been drunk at least once in the previous month or having had sex before the age of 16 were more likely to engage in sex under risky conditions. Moreover, girls who reported smoking and higher extroversion were more likely to engage in such types of sexual risk behaviour (see Tables 2, 3). Introducing these variables in a multiple logistic regression model with forward selection resulted in all of them being selected. The resulting mutually adjusted odds ratios are presented in Table 4.

\section{Multiple sexual partners}

The risk of multiple sexual partners was associated with more psychological factors among females. Males reporting having been drunk at least once in the preceding month or reporting sexual experience before age 16 were more likely to have had more than 3 sexual partners in their life. Extroversion was associated with multiple sexual partners among males, with a rather high though not statistically significant OR for the 'high extroversion' category.

Females reporting smoking or reporting sexual experience before age 16 were more likely to have had more than 3 sexual partners. Females reporting high extroversion and religiousness as unimportant were more likely to have had multiple sexual partners in comparison to their peers 
Table 2: Determinants of SRB in males $(n=184)$ : odds ratios $(\mathrm{OR})$ and $95 \%$-confidence intervals $(\mathrm{Cl})$

\begin{tabular}{|c|c|c|c|c|c|c|c|c|c|c|c|c|}
\hline & \multicolumn{4}{|c|}{ Sex in risky conditions } & \multicolumn{4}{|c|}{ Multiple sexual partners } & \multicolumn{4}{|c|}{ Inconsistent condom use } \\
\hline & $\mathbf{n}$ & $\%$ & OR & $95 \% \mathrm{Cl}$ & $\mathbf{n}$ & $\%$ & OR & $95 \% \mathrm{Cl}$ & $\mathbf{n}$ & $\%$ & OR & $95 \% \mathrm{Cl}$ \\
\hline \multicolumn{13}{|c|}{$\begin{array}{l}\text { Being drunk at least once during last } \\
\text { month }\end{array}$} \\
\hline No & 32 & 33.7 & 1.00 & & 17 & 19.3 & 1.00 & & 61 & 64.9 & 1.00 & \\
\hline Yes & 48 & 55.2 & $2.42 * *$ & $|.33-4.4|$ & 28 & 34.6 & $2.21^{*}$ & $1.10-4.44$ & 69 & 80.2 & $2.20 *$ & $1.11-4.33$ \\
\hline \multicolumn{13}{|c|}{ Smoke at least one cigarette per week } \\
\hline No & 44 & 43.6 & 1.00 & & 17 & 18.3 & 1.00 & & 69 & 69.0 & 1.00 & \\
\hline Yes & 36 & 45.6 & 1.09 & $0.60-1.96$ & 27 & 36.5 & 2.57 & $|.27-5.2|$ & 60 & 76.9 & 1.50 & $0.76-2.94$ \\
\hline \multicolumn{13}{|c|}{ Having sex before age of 16} \\
\hline No & 66 & 41.0 & 1.00 & & 37 & 23.9 & 1.00 & & 114 & 70.8 & 1.00 & \\
\hline Yes & 12 & 80.0 & $5.76 * *$ & $1.56-21.20$ & 8 & 66.7 & $6.38^{* * *}$ & $1.82-22.39$ & 13 & 86.7 & 2.68 & $0.58-12.34$ \\
\hline \multicolumn{13}{|l|}{ Self-esteem } \\
\hline High & 19 & 37.3 & 1.00 & & 16 & 33.3 & 1.00 & & 33 & 66.0 & 1.00 & \\
\hline Middle & 46 & 46.5 & 1.46 & $0.73-2.92$ & 23 & 25.3 & 0.68 & $0.32-1.45$ & 76 & 77.6 & 1.78 & $0.84-3.78$ \\
\hline Low & 12 & 44.4 & 1.35 & $0.52-3.48$ & 5 & 19.2 & 0.48 & $0.15-1.50$ & 18 & 66.7 & 1.03 & $0.38-2.78$ \\
\hline \multicolumn{13}{|l|}{ Well-being } \\
\hline High & 20 & 40.0 & 1.00 & & 14 & 32.6 & 1.00 & & 33 & 66.0 & 1.00 & \\
\hline Middle & 50 & 49.0 & 1.44 & $0.73-2.87$ & 23 & 24.0 & 0.65 & $0.30-1.44$ & 77 & 77.0 & 1.73 & $0.82-3.64$ \\
\hline Low & 10 & 33.3 & 0.75 & $0.29-1.93$ & 8 & 26.7 & 0.75 & $0.27-2.11$ & 20 & 66.7 & 1.03 & $0.40-2.69$ \\
\hline \multicolumn{13}{|l|}{ Extroversion } \\
\hline Low & 7 & 33.3 & 1.00 & & 3 & 14.3 & 1.00 & & 14 & 70.0 & 1.00 & \\
\hline Middle & 33 & 38.4 & 1.25 & $0.46-3.41$ & 14 & 17.7 & 1.29 & $0.33-4.99$ & 59 & 69.4 & 0.97 & $0.34-2.81$ \\
\hline High & 36 & 52.9 & 2.25 & $0.8 \mathrm{I}-6.27$ & 26 & 40.6 & $4.1 I^{*}$ & $1.10-15.37$ & 50 & 73.5 & 1.19 & $0.40-3.57$ \\
\hline \multicolumn{13}{|l|}{ Neuroticism } \\
\hline Low & 25 & 41.7 & 1.00 & & 15 & 27.3 & 1.00 & & 47 & 78.3 & 1.00 & \\
\hline Middle & 43 & 48.3 & 1.31 & $0.68-2.53$ & 21 & 25.0 & 0.89 & $0.41-1.92$ & 58 & 66.7 & 0.55 & $0.26-1.18$ \\
\hline High & 13 & 39.4 & 0.91 & $0.38-2.17$ & 9 & 29.0 & 1.09 & $0.4 I-2.90$ & 25 & 75.8 & 0.86 & $0.32-2.36$ \\
\hline \multicolumn{13}{|l|}{ Religiousness } \\
\hline Strongly important & 30 & 46.9 & 1.00 & & 22 & 36.1 & 1.00 & & 45 & 70.3 & 1.00 & \\
\hline Unimportant & 42 & 48.8 & 1.08 & $0.57-2.07$ & 17 & 21.8 & 0.49 & $0.23-1.05$ & 63 & 75.0 & 1.21 & $0.59-2.49$ \\
\hline
\end{tabular}

$*$ p. $<.05 . * *$ p. $<.01 * * *$ p. $<.001$

reporting a low level of extroversion or a high level of religiousness. Introducing these variables into a multiple logistic regression model with forward selection resulted in all of them being significant, except for having sex before age of 16 in the female sample. The resulting mutually adjusted odds ratios are presented in Table 4.

\section{Inconsistent condom use}

Only one behavioural factor in males (being drunk) and one in females (smoking) was associated with inconsistent condom use. Introducing this variable into a multiple logistic regression model with forward selection resulted in selection of only this variable.

\section{Discussion}

This study on SRB in young adults in CEE shows that the occurrence of SRB in Slovak young adults varies from 21 to $81 \%$ of sexually experienced respondents $(n=455)$, depending on the indicator used. The most frequently reported SRB is inconsistent condom use, despite the fact that consistent condom use is one of the most efficient ways of protection. The occurrence of sexual intercourse under risky conditions is also very high, varying between
$33-44 \%$ of the sexually experienced. From 5 to $9 \%$ of respondents reported having already had sex before age 16 , and $27 \%$ of males and $21 \%$ of females reported having had multiple sexual partners.

From an international point of view, Slovak students have their sexual initiation exceptionally late, and the number of their sexual partners is low. On the other hand, similar to other studies, no gender differences were found in the prevalence of having sex. These findings fit with those from the HBSC study, where a lower proportion of sexually experienced individuals was reported among 14 and 15 years old adolescents in Central European countries (Hungary, Czech Republic, Croatia, Poland) compared with adolescents from Western or Northern European countries [1].

In line with several other studies [37-40], our study shows that alcohol use is one of the most consistent predictors of SRB. This finding supports the explanations that less selfcontrol leads to risk behaviour and that certain people have a psychological predisposition to seek sensation and are thus more likely than others to engage in a variety of 
Table 3: Determinants of SRB in females $(n=27$ ): odds ratios $(O R)$ and 95\%-confidence intervals $(C I)$

\begin{tabular}{|c|c|c|c|c|c|c|c|c|c|c|c|c|}
\hline & \multicolumn{4}{|c|}{$\underline{\text { Sex in risky conditions }}$} & \multicolumn{4}{|c|}{ Multiple sexual partners } & \multicolumn{4}{|c|}{ Inconsistent condom use } \\
\hline & $\mathbf{n}$ & $\%$ & OR & $95 \% \mathrm{Cl}$ & $\mathbf{n}$ & $\%$ & OR & $95 \% \mathrm{Cl}$ & $\mathbf{n}$ & $\%$ & OR & $95 \% \mathrm{Cl}$ \\
\hline \multicolumn{13}{|c|}{$\begin{array}{l}\text { Being drunk at least once during last } \\
\text { month }\end{array}$} \\
\hline No & 45 & 24.2 & 1.00 & & 34 & 19.1 & 1.00 & & $|4|$ & 77.9 & 1.00 & \\
\hline Yes & 41 & 52.6 & $3.47^{* * *}$ & $1.99-6.06$ & 20 & 27.4 & 1.60 & $0.85-3.02$ & 68 & 87.2 & 1.93 & $0.91-4.09$ \\
\hline \multicolumn{13}{|c|}{$\begin{array}{l}\text { Smoke at least one cigarette per } \\
\text { week }\end{array}$} \\
\hline No & 33 & 20.9 & 1.00 & & 21 & 14.0 & 1.00 & & 118 & 76.1 & 1.00 & \\
\hline Yes & 53 & 53.0 & $4.27^{* * *}$ & $2.47-7.40$ & 33 & 34.7 & $3.27^{* * *}$ & $1.75-6.11$ & 86 & 88.7 & $2.45^{*}$ & $1.18-5.08$ \\
\hline \multicolumn{13}{|c|}{ Having sex before age of 16} \\
\hline No & 73 & 30.2 & 1.00 & & 47 & 19.8 & 1.00 & & 189 & 79.7 & 1.00 & \\
\hline Yes & 11 & 84.6 & $12.73^{* * * *}$ & $2.75-58.89$ & 7 & 53.8 & $4.72^{* *}$ & $1.51-14.69$ & 12 & 92.3 & 3.05 & $0.39-24.02$ \\
\hline \multicolumn{13}{|l|}{ Self-esteem } \\
\hline High & 21 & 31.8 & 1.00 & & 14 & 21.9 & 1.00 & & 51 & 79.7 & 1.00 & \\
\hline Middle & 47 & 35.6 & 1.19 & $0.63-2.22$ & 28 & 22.0 & 1.01 & $0.49-2.09$ & 102 & 79.1 & 0.96 & $0.46-2.02$ \\
\hline Low & 16 & 27.6 & 0.82 & $0.38-1.77$ & 11 & 21.2 & 0.96 & $0.39-2.34$ & 50 & 87.7 & 1.82 & $0.67-4.94$ \\
\hline \multicolumn{13}{|l|}{ Well-being } \\
\hline High & 19 & 33.9 & 1.00 & & 15 & 27.3 & 1.00 & & 42 & 75.0 & 1.00 & \\
\hline Middle & 39 & 30.2 & 0.84 & $0.43-1.65$ & 28 & 23.1 & 0.80 & $0.39-1.66$ & 101 & 81.5 & 1.46 & $0.69-3.12$ \\
\hline Low & 29 & 37.7 & 1.18 & $0.57-2.42$ & 11 & 15.1 & 0.47 & $0.20-1.13$ & 64 & 84.2 & 1.78 & $0.75-4.22$ \\
\hline \multicolumn{13}{|l|}{ Extroversion } \\
\hline Low & 6 & 17.1 & 1.00 & & 2 & 5.9 & 1.00 & & 26 & 76.5 & 1.00 & \\
\hline Middle & 29 & 25.9 & 1.69 & $0.64-4.48$ & 18 & 16.8 & 3.24 & $0.71-14.73$ & 88 & 78.6 & 1.13 & $0.45-2.81$ \\
\hline High & 48 & 47.1 & $4.30 * *$ & $1.64-11.23$ & 33 & 34.7 & $8.52^{* *}$ & $1.92-37.76$ & 81 & 83.5 & 1.56 & $0.60-4.06$ \\
\hline \multicolumn{13}{|l|}{ Neuroticism } \\
\hline Low & 12 & 25.5 & 1.00 & & 9 & 20.0 & 1.00 & & 35 & 77.8 & 1.00 & \\
\hline Middle & 43 & 33.3 & 1.46 & $0.69-3.09$ & 27 & 21.3 & 1.08 & $0.46-2.52$ & 107 & 83.6 & 1.46 & $0.63-3.39$ \\
\hline High & 31 & 38.3 & 1.81 & $0.82-4.00$ & 18 & 24.7 & 1.31 & $0.53-3.23$ & 60 & 75.9 & 0.90 & $0.38-2.16$ \\
\hline \multicolumn{13}{|l|}{ Religiousness } \\
\hline Extremely important & 25 & 26.3 & 1.00 & & 10 & 11.0 & 1.00 & & 75 & 79.8 & 1.00 & \\
\hline Unimportant & 48 & 38.1 & 1.72 & $0.96-3.08$ & 36 & 29.5 & $3.39 * *$ & $1.58-7.28$ & 98 & 79.0 & 0.96 & $0.49-1.85$ \\
\hline
\end{tabular}

$*$ p. $<.05 . * *$ p. $<.01 * * *$ p. $<.001$

risk behaviours [41]. However, without contextual information about this event, we cannot clearly state that alcohol or drug use has a causal relation to SRB. It should be noted that our measurement of having sex under risky conditions covers lifetime history, which might be the reason for the high proportion, but on the other hand, lifetime history in this age group represents only about 4 years of life. Future analyses should go more deeply into the dimensions of a relationship like trust, intimacy, commitment and communication and their effect on behaviour. Our approach is important especially among the young population, where the age of the first contact with alcohol consumption is rapidly dropping [1].

The study results also revealed relevant differences between male and female sexual behaviour. Males report mostly behavioural factors as significant predictors for sex under risky conditions and multiple sexual partners. On the other hand, females add psychological factors. Their lower levels of extroversion and higher levels of religiousness are associated with fewer sexual partners, in accord- ance with other studies $[42,43]$, where religiousness seems to be a protective factor against a high number of sexual partners among girls. On the border of statistical significance was the association between a high level of religiousness and a low probability of having sex under risky conditions. Thus, it is probably not only religiousness that plays an important role. Several studies have shown that girls who report a high importance of religiousness probably live in such psychosocial and cultural environments (personality, relationships, family, friends, and school) that opportunities for SRB are rather limited $[44,45]$. On the other hand religiousness had no significant association with sex under risky conditions or inconsistent condom use, which suggests that among those who have already had sexual intercourse, religiousness does not play a role. We can conclude, then, that despite the high importance of religiousness among students, their sexual behaviour reflects strategies more risky than safe.

Inconsistent condom use has been frequently reported as a major pattern of SRB. Only those who reported consist- 
Table 4: Factors associated with SRB after forward selection: odds ratios (OR) and 95\%-confidence intervals (Cl) '

\begin{tabular}{|c|c|c|c|c|}
\hline \multirow[b]{2}{*}{ Males } & \multicolumn{2}{|c|}{ Sex in risky conditions } & \multicolumn{2}{|c|}{ Multiple sexual partners } \\
\hline & OR & $95 \% \mathrm{Cl}$ & OR & $95 \% \mathrm{Cl}$ \\
\hline \multicolumn{5}{|c|}{ Being drunk at least once during last month } \\
\hline No & 1.00 & $* *$ & 1.00 & $* *$ \\
\hline Yes & 2.48 & $1.32-4.64$ & 2.25 & $1.04-4.88$ \\
\hline \multicolumn{5}{|c|}{ Having sex before age of 16} \\
\hline No & 1.00 & ** & 1.00 & $* *$ \\
\hline Yes & 5.97 & $1.58-22.53$ & 6.41 & $1.73-23.80$ \\
\hline \multicolumn{5}{|l|}{ Extroversion } \\
\hline Low & & & 1.00 & $*$ \\
\hline Middle & & & 1.22 & $0.29-5.10$ \\
\hline High & & & 3.50 & $0.87-14.13$ \\
\hline \multicolumn{5}{|l|}{ Females } \\
\hline \multicolumn{5}{|c|}{ Being drunk at least once during last month } \\
\hline No & 1.00 & $* *$ & & \\
\hline Yes & 2.41 & $1.30-4.46$ & & \\
\hline \multicolumn{5}{|c|}{ Smoke at least one cigarette per week } \\
\hline No & 1.00 & $* * *$ & 1.00 & * \\
\hline Yes & 3.00 & $1.66-5.44$ & 2.55 & $1.20-5.40$ \\
\hline \multicolumn{5}{|c|}{ Having sex before age of 16} \\
\hline No & 1.00 & $*$ & 1.00 & \\
\hline Yes & 7.18 & $1.46-35.38$ & 3.57 & $0.91-14.02$ \\
\hline \multicolumn{5}{|l|}{ Extroversion } \\
\hline Low & 1.00 & $*$ & 1.00 & $* *$ \\
\hline Middle & 1.42 & $0.48-4.17$ & 2.80 & $0.56-14.16$ \\
\hline High & 2.96 & $1.03-8.48$ & 8.22 & $1.69-40.03$ \\
\hline \multicolumn{5}{|l|}{ Religiousness } \\
\hline Extremely important & & & 1.00 & $*$ \\
\hline Unimportant & & & 2.82 & $1.24-6.45$ \\
\hline
\end{tabular}

I ORs in bold indicates that overall a variable contributes to the logistic model at $*$ p. $<.05 . * *$ p. $<.01 * * *$ p. $<.001$

ent condom use were defined as a safe group; all others were defined as a risk group. This strict criterion comes from the assumption that each intercourse without a condom is risky in terms of STI infection or unintended pregnancy. Of course, such a definition cannot be used in each age group, but among first year university students, 90\% of whom are in the 19-23 age range and where it is difficult to expect stable and long lasting sexual partnerships or unprotected intercourse with the aim of becoming pregnant, this methodical criterion should fit. Despite the high rates of inconsistent condom use in our sample (72.4\% of males and $80.7 \%$ of females), we only found an association with drinking in males and smoking in females. These results are in accordance with previous research $[8,46,47]$, which showed alcohol consumption to be negatively associated with condom use. Nevertheless, recent studies have recognized the importance of examining how sexual relationships themselves influence condom use. It is possible that alcohol only has an effect on condom use at specific phases in a relationship [48].

Studies which explored the role of alcohol use on condom use [49-51] and studies which assessed the length of a relationship [52] or the type of relationship [53] did not find any association between alcohol consumption and condom use. Moreover, these results do not support the persistent notion that alcohol causes people to engage in sexual risk that they would avoid when sober. Instead, people tend to follow their usual pattern of condom use, regardless of alcohol use [50]. Such inconsistent findings regarding condom use and drinking suggest the possible effect of a third factor which affects both variances, and that any relationship between condom use and drinking is disputable. Mental health problems, developmental factors, disposition to risk taking and sensation seeking, familial influences and general tolerance for deviance have all been reported as possible third variances in literature sources [54-57]. Consequently, an association between alcohol use and condom use could be attributable to these factors and not to any relationship between alcohol and condom use [48]. Nevertheless, our results suggest that behavioural factors are more closely related to SRB than psychological ones. 


\section{Methodological considerations}

This study has several strengths and limitations. Due to possible methodological problems, studies of sexual behaviour in CEE countries are rare. We obtained a very high response rate (94\%), however, by using the setting of lectures, so selection bias is very unlikely to occur. We cannot exclude information bias, however, though we did use specific measures to guarantee confidentiality. These measures have been shown to yield valid outcomes.

Regarding multiple sexual partners among males, the combination of $95 \%$-confidence intervals of both the 'middle' and the 'high' categories of extroversion comprising '1' (i.e. are not statistically significant different from the reference category) but at the same time extroversion contributing to the model with statistical significance seems odd. It can be explained by the fact that the associations of the middle and the high categories with the outcome differ quite a lot too. The latter has been taken into account regarding the overall p-value, but not regarding the comparison of these separate categories with the same reference category (i.e. 'low') and the resulting 95\%-confidencence intervals. This holds for any logistic regression in which dummy coding is used for separate categories (like we did).

\section{Implications}

Our findings support the hypothesis that risk behaviours tend to cumulate, e.g. sexual risk behaviour may coincide with binge drinking and smoking. However, one of our indicators for SRB (having sex under risky conditions, e.g. after a short relationship or under the influence of drug or alcohol consumption) may overlap with one of the explored independent variables (being drunk). To understand whether alcohol has an effect on adolescents' condom use, future research should consider whether adolescents are drinking at the time that the decision is made, because it may be that alcohol negates any skill learned while sober [48].

Additional research is needed to assess whether other factors so we may suppose that smoking or binge drinking increase the contribute to consistent use of condoms, such as the level of health awareness, self-efficacy and anxiety related to health risk, or participation in SRB while accepting the risk involved in such behaviour. However, we did not find any associations between self-esteem and consistent or inconsistent condom use, which contrasts with the findings of several studies [58,59]. Particularly in this case, our findings should be interpreted with this special aspect in mind. However, we confirmed the associations of drinking and smoking on SRB, probability of SRB, or, in other words, that they are risk indicators with regard to $\mathrm{SRB}$ in any case.

\section{Conclusion}

The overall findings of our study suggest that the specification of SRB into three indicators contributes to a better understanding and description of SRB. All three indicators provide a specific and different view on adolescent sexual behaviour. Consequently, several significant differences were found between the indicators, which suggest an important variance in SRB and allows several recommendations to be formulated. Systematic prevention should be focused on the high incidence of sexual risk behaviour among young people, which indicates the need for health promotion programmes not only on smoking, alcohol and drugs, for example, but that sexual risk behaviour should also be integrated into prevention programmes. Due to the accumulation of risk behaviour among young people, focusing on prevention in a related set of unhealthy behaviours instead of a single type of unhealthy behaviour will be very important, particularly in early adolescence. Moreover, results show a high need for health promotion programmes in early adolescence that target SRB in conjunction with other health-related risk behaviours such as alcohol abuse.

\section{Competing interests}

The authors declare that they have no competing interests.

\section{Authors' contributions}

OK carried out the data collection, did the analysis, interpreted the data, and drafted the manuscript. AMG participated in the design and the coordination of the study and helped to draft the manuscript. PJ participated in the design of the study and questionnaire and helped to draft the manuscript. OO participated in the data collection, in coordination and helped to draft the manuscript. JPvD participated in the design of the study and helped to draft the manuscript. SAR commented on the design of the study, contributed to the statistical analysis and drafted the final version of the manuscript. All authors read and approved the final manuscript.

\section{Acknowledgements}

This publication was supported by the Research Grant Agency of the Ministry of Education and Slovak Academy of Sciences under contract VEGA I/ 1408/04, and the Research and Development Support Agency under contract No. APVT-(20-028802).

\section{References}

I. Currie C, Roberts C, Morgan A, Smith R, Settertobulte W, Samdal O, Barnekow Rasmussen V: Young People's Health in Context: international report from the HBSC 2001/02 survey Copenhagen: WHO Regional Office for Europe; 2004.

2. Kegeles SM, Adler NE, Irwin CE Jr: Sexually active adolescents and condoms: changes over one year in knowledge, attitudes and use. Am J Public Health 1988, 78:460-46I.

3. Moore S, Rosenthal D: The social context of adolescent sexuality: safe sex implications. J Adolesc 1992, I 5:4 I5-435.

4. Morrison DM, Baker SA, Gillmore MR: Sexual risk behavior, knowledge, and condom use among adolescents in juvenile detention. J Youth Adolesc 1994, 23:27I-288. 
5. Metzler CW, Noell J, Biglan A, Ary D, Smolkowski K: The social context for risky sexual behavior among adolescents. J Behav Med 1994, I 7:419-438.

6. Sieving R, Resnick MD, Bearinger L, Remafedi G, Taylor BA, Harmon $B$ : Cognitive and behavioral predictors of sexually transmitted disease risk behavior among sexually active adolescents. Arch Pediatr Adolesc Med I997, I 5 I:243-25I.

7. Lowry R, Holtzman D, Truman BI, Kann L, Collins JL, Kolbe LJ: Substance use and HIV-related sexual behaviors among US high school students: are they related? Am J Public Health 1994, 84: I I I6-I I 20.

8. Tapert SF, Aarons GA, Sedlar GR, Brown SA: Adolescent substance use and sexual risk-taking behavior. J Adolesc Health 2001, 28:181-189.

9. Hibell B, Bjarnason T, Kokkevi A, Morgan M, Narusk A: The 1995 ESPAD Report. Alcohol and Other Drug Use Among Students in 26 European Countries Stockholm: Swedish Council for Information on Alcohol and Other Drugs for Information on Alcohol and Other Drugs; 1997.

10. Hibell B, Anderson B, Ahlstrom S, Balakireva O, Bjarnason T, Kokkevi A, Morgan A: The 1999 ESPAD Report. Alcohol and Other Drugs Use Among Students in 30 European Countries Stockholm: Swedish Council for Information on Alcohol and Other Drugs; 2000.

II. Hibell B, Anderson B, Bjarnason T, Ahlstrom S, Balakireva O, Kokkevi A, Morgan A: The ESPAD Report 2003. Alcohol and Other Drug Use Among Students in 35 European Countries Stockholm: Swedish Council for Information on Alcohol and Other Drugs; 2004.

12. Hibell B, Anderson B, Beck F, Choquet M, Kokkevi A, Fotiou A, Molaniro S, Nociar A, Sieroslawski J, Trapencieris M: The ESPAD Report 2007. Alcohol and Drug Use Among European I7-I 8 Year Old Students Stockholm: Swedish Council for Information on Alcohol and Other Drugs; 2008.

13. Smith CA: Factors associated with early sexual activity among urban adolescents. Soc Work 1997, 42:334-346.

14. Kotchick BA, Shaffer A, Forehand R, Miller KS: Adolescent sexual risk behavior: a multi-system perspective. Clin Psychol Rev 200I, 21:493-519.

15. Mardh PA, Creatsas G, Guaschino S, Hellberg D, Henry-Suchet J: Correlation between an early sexual debut, and reproductive health and behavioral factors: a multinational European study. Eur J Contracept Reprod Health Care 2000, 5: I77-I82.

16. Albert B, Brown S, Flanigan C: 14 and Younger: The Sexual behavior of Young Adolescents (Summary). Washinghton, DC: National Campaign to Prevent Teen Pregnancy; 2003.

17. Jessor R: Risk behavior in adolescence: a psychosocial framework for understanding and action. J Adolesc Health 199I, 1 2:597-605.

18. Jessor R: Problem-behavior theory, psychosocial development, and adolescent problem drinking. $\mathrm{Br} J$ Addict 1987, 82:331-342.

19. Hoyle RH: Personality processes and problem behavior. J Pers 2000, 68:953-966.

20. Reitman D, St Lawrence JS, Jefferson KW, Alleyne E, Brasfield TL, Shirley A: Predictors of African American adolescents' condom use and HIV risk behavior. AIDS Educ Prev 1996, 8:499-5 I 5

21. Santelli JS, Lowry R, Brener ND, Robin L: The association of sexual behaviors with socioeconomic status, family structure, and race/ethnicity among US adolescents. Am J Public Health 2000, 90: I582-1588.

22. Petridou E, Zavitsanos X, Dessypris N, Frangakis C, Mandyla M, Doxiadis S, Trichopoulos D: Adolescents in high-risk trajectory: clustering of risky behavior and the origins of socioeconomic health differentials. Prev Med 1997, 26:215-219.

23. Harvey SM, Spigner C: Factors associated with sexual behavior among adolescents: a multivariate analysis. Adolescence 1995, 30:253-264.

24. Luster T, Small S: Factors associated with sexual risk-taking behaviours among adolescents. Journal of Marriage and the Family 1994, 54:622-632.

25. Orr DP, Beiter M, Ingersoll G: Premature sexual activity as an indicator of psychosocial risk. Pediatrics I991, 87:|41-147.

26. Tubman JG, Windle M, Windle RC: The onset and cross-temporal patterning of sexual intercourse in middle adolescence: prospective relations with behavioral and emotional problems. Child Dev 1996, 67:327-343.
27. Howard DE, Wang MQ: Multiple sexual-partner behavior among sexually active US adolescent girls. Am J Health Behav 2004, 28:3-12.

28. Edwards A, Curtis S, Sherrard J: Survey of risk behaviour and HIV prevalence in an English prison. Int J STD AIDS 1999, 1 0:464-466.

29. Santelli JS, Brener ND, Lowry R, Bhatt A, Zabin LS: Multiple sexua partners among U.S. adolescents and young adults. Fam Plann Perspect 1998, 30:27|-275

30. Geckova A, van Dijk JP, van Ittersum-Gritter T, Groothoff JW, Post $D$ : Determinants of adolescents' smoking behaviour: a literature review. Cent Eur I Public Health 2002, 10:79-87.

31. Tuinstra J, Groothoff JW, Heuvel WJ van den, Post D: Socio-economic differences in health risk behavior in adolescence: do they exist? Soc Sci Med 1998, 47:67-74.

32. Sleskova M, Salonna F, Madarasova GA, van Dijk JP, Groothoff JW: Health status among young people in Slovakia: comparisons on the basis of age, gender and education. Soc Sci Med 2005, 6 I :252 I-2527.

33. Rosenberg M: Society and the Adolescent self-image Princeton, New Jersey: Princeton University Press; 1965.

34. Goldberg DP, Hillier VF: A scaled version of the General Health Questionnaire. Psychol Med 1979, 9:139-145.

35. Navratil M, McGuckin C, Lewis C, Shevlin M, Francis L: Confirmatory factor analysis of the Czech translation of abbreviated form of the Revised Exsenck Personality Questionnaire (EPQR-A) among Czech students. Ceskoslovesnka Psychologie 2003, 47:45 I-459.

36. Rokeach $\mathrm{M}$ : A value approach to the prevention and reduction of drug abuse. NIDA Res Monogr 1983, 47:172-194.

37. Brown TL, Parks GS, Zimmerman RS, Phillips CM: The role of religion in predicting adolescent alcohol use and problem drinking. J Stud Alcohol 200I, 62:696-705

38. Cooper ML, Peirce RS, Huselid RF: Substance use and sexual risk taking among black adolescents and white adolescents. Health Psychol 1994, 13:251-262.

39. Fullilove MT, Golden E, Fullilove RE III, Lennon R, Porterfield D, Schwarcz S, Bolan G: Crack cocaine use and high-risk behaviors among sexually active black adolescents. J Adolesc Health 1993, 1 4:295-300.

40. Millstein SG, Moscicki AB: Sexually-transmitted disease in female adolescents: effects of psychosocial factors and high risk behaviors. J Adolesc Health 1995, I 7:83-90.

41. Zuckerman M: Sensation seeking and behavior disorders. Arch Gen Psychiatry 1988, 45:502-504.

42. Bingham CR, Crockett LJ: Longitudinal adjustement patterns of boys and girls experiencing early, middle, and late sexual intercourse. Developmental Psychology 1996, 32:647-658.

43. Crockett LJ, Bingham CR, Chopak JS, Vicary JR: Timing of first sexual intercourse: the role of social control, social learning, and problem behavior. I Youth Adolesc 1996, 25:89- I I I.

44. Moser AM, Reggiani C, Urbanetz A: [Risky sexual behavior among university students in health science courses]. Rev Assoc Med Bras 2007, 53: I I6-121.

45. Wink P, Ciciolla L, Dillon M, Tracy A: Religiousness, spiritual seeking, and personality: findings from a longitudinal study. J Pers 2007, 75:1051-1070.

46. Castilla J, Barrio G, Belza MJ, de la Fuente L: Drug and alcohol consumption and sexual risk behaviour among young adults: results from a national survey. Drug Alcohol Depend 1999, 56:47-53.

47. McEwan RT, McCallum A, Bhopal RS, Madhok R: Sex and the risk of HIV infection: the role of alcohol. Br J Addict 1992, 87:577-584.

48. Halpern-Felsher BL, Millstein SG, Ellen JM: Relationship of alcohol use and risky sexual behavior: a review and analysis of findings. J Adolesc Health 1996, I 9:331-336.

49. Dye C, Upchurch DM: Moderating effects of gender on alcohol use: implications for condom use at first intercourse. J Sch Health 2006, 76: I II-1 I6.

50. Leigh BC, Vanslyke JG, Hoppe MJ, Rainey DT, Morrison DM, Gillmore MR: Drinking and condom use: results from an event-based daily diary. AIDS Behav 2008, I 2: 104- I I 2.

51. Leigh BC: Alcohol and condom use: a meta-analysis of eventlevel studies. Sex Transm Dis 2002, 29:476-482. 
52. Kraft P, Rise J: Contraceptive behaviour of Norwegian adolescents. Health Educ Res 199I, 6:43 I-44I.

53. Senf $J \mathrm{H}$, Price CQ: Young adults, alcohol and condom use: what is the connection? J Adolesc Health 1994, 15:238-244.

54. Hamburg BA, Kraemer HC, Jahnke W: A hierarchy of drug use in adolescene: behavioral and attitudinal correlates of substantial drug use. Am J Psychiatry 1975, I32: I I55-I I 63.

55. Jessor R, Chase JA, Donovan JE: Psychosocial correlates of marijuana use and problem drinking in a national sample of adolescents. Am J Public Health 1980, 70:604-6I3.

56. Zuckerman $M$, Neeb M: Sensation seeking and psychopathology. Psychiatry Res 1979, I:255-264.

57. Tschann JM, Adler NE, Irwin CE Jr, Millstein SG, Turner RA, Kegeles SM: Initiation of substance use in early adolescence: the roles of pubertal timing and emotional distress. Health Psychol I994, 13:326-333.

58. McNair LD: Self-esteem, gender, and alcohol use: relationships with HIV risk perception and behaviors in college students. J Sex Marital Ther 1998, 24:29-36.

59. Pleck JH, Sonenstein FL, Ku LC: Contraceptive attitudes and intention to use condoms in sexually experienced and inexperienced adolescent males. J Fam Issues 1990, I I:294-3 I2.

\section{Pre-publication history}

The pre-publication history for this paper can be accessed here:

http://www.biomedcentral.com/1471-2458/9/15/prepub

Publish with Bio Med Central and every scientist can read your work free of charge

"BioMed Central will be the most significant development for disseminating the results of biomedical research in our lifetime."

Sir Paul Nurse, Cancer Research UK

Your research papers will be:

- available free of charge to the entire biomedical community

- peer reviewed and published immediately upon acceptance

- cited in PubMed and archived on PubMed Central

- yours - you keep the copyright

Submit your manuscript here:

http://www.biomedcentral.com/info/publishing_adv.asp 